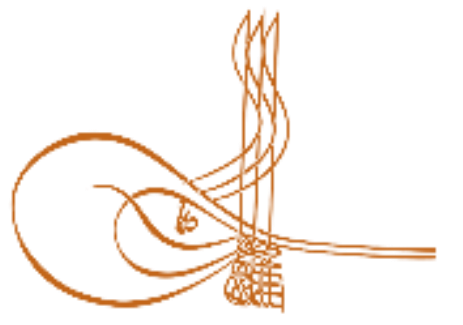

www.turkishstudies.net/turkishstudies
Turkish Studies

eISSN: $1308-2140$

Research Article / Araştırma Makalesi

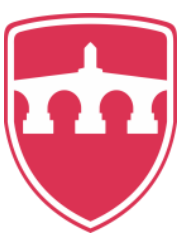

INTERNATIONAL

BALKAN

UNIVERSITY

Sponsored by IBU

\title{
Modernleşme Yolunda Amerikan Sanat Gruplarının Reformist Çabaları
}

Reformist Efforts of American Art Groups on the Modernization Way

\author{
Yusuf Emre Iş1k ${ }^{*}$ - Mustafa Işık ${ }^{* *}$
}

\begin{abstract}
This study includes the analysis of the efforts undertaken in terms of the results of the exhibition of the European avant-garde artists at the Armory Show in the period from Impressionism to Cubism. Unlike the objective reality of traditionalist art, the works exhibited at the Armory Show were unique examples of individual interpretations of avant-garde artists towards abstraction. The realism criteria of the modern works of art exhibited in the Armory Show in 1913 caused an abrupt anger and excitement among critics and artists who had difficulty at first grasping. As the problems were overcome, American art responded to changes in visual arts in Europe, which emerged in the early twentieth century. Art critics challenged the changes in the visual arts represented at the Armory Show, and in time, changed their aesthetic perception and philosophies. Armory Show exhibition, which includes works of European artists as well as American artists; Before art movements such as Abstract Expressionism, Pop Art and Minimalism, which constituted American art, they represented the first examples of modern art in the history of the USA. The realistic movement gathered around the artist Robert Henri and the Ashcan School, who challenged the National Academy of Design, "The Eight" group's revolutionary exhibition in the USA in 1908, Alfred Stieglitz introducing the works of European modern artists in "Gallery 291", 1910 Exhibition of Independent Artists seen as the pioneering efforts of artists. These activities had an impact on the creation of avant-garde art in the USA by preparing the ground for designing the 1913 Armory Show exhibition.
\end{abstract}

Structured Abstract: America was not yet familiar with the modern art movement that started in Europe in the early years of the 20th century. The artists with a traditionalist perspective depicting landscape and natural life in America could not resist the challenge of an independent group of artists (Ashcan School), which came to the fore with urban life themes in New York in the early 20th century (Zilczer, 1975: 2-3). Five painters from the Ashcan group and three independent artists (Ernest Lawson, Arthur B. Davies, Maurice Prendergast) created the "The Eight" group. In 1908, "The Eight" organized a historical exhibition that became a symbol of rebellion in American and modern art as a protest against the restrictive attitudes of academism. The exhibition was a revolution since it was the first exhibition organized by a group of artists without a jury and awards. This

\footnotetext{
* Arş. Gör. Dr., Trabzon Üniversitesi, Güzel Sanatlar Fakültesi, Resim Bölümü Res. Asst. Dr., Trabzon University, Faculty of Fine Arts, Department of Painting ORCID 0000-0001-6876-7310

yusufemreisik@outlook.com

** Doç. Dr., Trabzon Üniversitesi, Fatih Eğitim Fakültesi, Güzel Sanatlar Eğitimi Bölümü Assoc. Prof. Dr., Trabzon University, Fatih Faculty of Education, Department of Fine Arts Education ORCID 0000-0001-8401-2823

bymustafaisik@gmail.com

Cite as/ Atıf: Işık, Y. E., Işık, M. (2020). Modernleşme yolunda Amerikan sanat gruplarının reformist çabaları, Turkish Studies, 15(2), 1027-1038. https://dx.doi.org/10.29228/TurkishStudies.41855

Received/Geliş: 19 February/Şubat 2020

Accepted/Kabul: 25 April/Nisan 2020 Checked by plagiarism software

Copyright $(\mathrm{C}$ MDE, Turkey Published/Yayın: 30 April/Nisan 2020 CC BY-NC 4.0
} 
kind of jury-free exhibition became a model for Armory Show, one of the most famous exhibitions in the history of Modern Art ("Artdaily", 2005). Young artists, who were uncomfortable with the inadequacy of the American art arena, which consisted of several traditional art associations, often came together and started to think solution-oriented. These artists criticized the stable and conservative structure of the National Academy of Design as the only art institution in America and were uncomfortable with the stillness (Baraz, 1998: 2). The exhibition project, which was launched in 1911 by four young American artists (Henry Fitch Taylor, Jerome Myers, Walt Kuhn and Elmer MacRae), had a surprisingly outstanding effect. With the desire to popularize new developments in American art among the young generation of artists who started the project, there was a sense of public awareness about the scope of America's contemporary art success.

The Armory Show (International Exhibition of Modern Art), opened by the American Association of Painters and Sculptors (AAPS) at the 69th Regiment Armory in New York between 17 February and 15 March 1913, had a strong shock effect on American art. Undoubtedly, this was the most important exhibition ever held in America.

From the late 19 th century to the early 20th century, the US underwent many changes in economic, social, cultural and industrial terms. Despite the uneasiness caused by the political insecurity in Europe, the shining economic prosperity in America created huge waves of immigration to the country. With European artists coming to New York and continuing their activities, the permanent effect of American tradition and culture began to weaken. From time to time, artists came together in certain venues and shared artistic ideas and tried to emerge with new understandings in the face of American traditional art with their potential. The artifacts, galleries and exhibitions opened constitute the art market, and America has begun to turn into a globalized international art scene on the way to becoming the center of art in New York.

At the beginning of the 20th century, a group of artists called Ashcan School and The Eight formed the core of American modernism. On the one hand, the artist Robert Henri, the group gathered around "Ashcan School", "The Eight", is disconnected from the Academy, while on the other hand is the photo-secession movement of Photographer Alfred Stieglitz (his photography as a branch of art) and "Camera Work" magazine has resulted in efforts to create modern American art. Considering Stieglitz's works in Europe's "Gallery 291”, one of Europe's famous artists, Paul Cézanne, Henri Matisse, Pablo Picasso's work to a brand new audience, the Armory Show exhibition, considering the leading role played by the rise of modernism in the USA it seems to be in a direct and structured relationship with today.

Exhibiting the paintings brought from Europe, we witness that the American artists started a process that was subject to many important developments and changes that prepared modern art as a result of years of experience and experience. In addition, by supporting the goal of the exhibition project initiated by the American Artists and Sculptors Association to promote new art in America, the efforts of European modern art works to create visual experience and awareness of American artists were encouraging steps for American artists. One of the most favorite of these steps is the effects of the Armory Show exhibition on American art and artist.

The most important success of Armory Show in creating modern American art is measured by the historical significance of the transformation created by works imported from a different continent. Distinguished Modern visual art works from Europe led to the perception of a new form of aesthetics on American artists. The introduction of new aesthetic forms based on concept and philosophy was in question. The sense of awareness created in the perception of a brand new aesthetic existence in art was the beginning of change for American artists, intellectuals and viewers.

In the modern art museums in Europe, Europe has brought the viewers through new windows by shedding light on their emotional and psychic situations. The Armory Show and the subsequent exhibitions have led American art curators to change their aesthetic consciousness. In addition, Armory Show created a visual art market in America and created a commercial effect. After the success of the Armory Show, new art galleries, publications, associations and modern art exhibitions have rapidly increased.

With the inspiration of American young generation artists from the Armory Show exhibition, they have gone to Europe and their perspective on art has changed. With the Armory Show exhibition, the tendency of US art towards traditionalism has weakened, while the tendencies towards modern art have increased significantly. 
The historical significance of the Armory Show is unmatched in US art history. Briefly, Armory Show, which is considered as the most important art exhibition in the history of the USA, became a turning point in the avant-garde art world. Modern art in America has managed to reconcile life with art from every stage of life.

Keywords: Modern Art, Avant-garde, Abstraction, Armory Show, New York

Öz: Bu çalışma Empresyonizmden Kübizme kadar ki dönemde Avrupa avangard sanatçıların eserleriyle Armory Show'da sergilenmesinin sonuçları açısından üstlenilen çabaların çeşitli safhalarda incelenmesini içermektedir. Gelenekçi sanatın objektif gerçekliğinin tam aksine Armory Show'da sergilenmiş olan yapıtlar, avangard sanatçıların soyutlamaya doğru bireysel yorumlamalarının eşsiz örneklerini oluşturuyordu. 1913'te Armory Show sergilenen modern sanat yapıtlarının gerçekçilik ölçütleri ilk başta kavrama güçlüğü çeken eleştirmen ve sanatçılarda ani bir öfke ve heyecana neden oldu. Sorunlar aşıldıkça Amerikan sanatı yirminci yüzyılın başlarında ortaya çıkan Avrupa'da görsel sanatlardaki değişimlere karşı cevap verdi. Sanat eleştirmenlerinin, Armory Show'da temsil edilen görsel sanatlardaki değişikliklere meydan okumaları zaman içinde estetik algı ve felsefelerini de değiştirmelerle yön buldu. Amerikan sanatçılarının yanı sıra Avrupalı modern sanatçıların yapıtlarının da yer aldığı Armory Show sergisi; Amerikan sanatını oluşturan Soyut Ekspresyonizm, Pop Art ve Minimalizm gibi sanat akımlarından önce ABD tarihinde modern sanatın ilk örneklerini temsil etmekteydi. Ulusal Tasarım Akademisi'ne meydan okuyan sanatçı Robert Henri ve Ashcan Okulu çevresinde toplanan gerçekçi hareket, “The Eight” grubunun 1908'de ABD'de devrim niteliğindeki sergisi, Alfred Stieglitz'in "Galeri 291"de Avrupalı modern sanatçıların eserlerini tanıtması, 1910'da "Bağımsız Sanatçılar Sergisi” New York sanat dünyasında yarattığı firtınalar sanatçıların öncü çabaları olarak görülmektedir. Bu faaliyetler 1913 Armory Show sergisi tasarlama fikrine zemin hazırlayarak ABD’de avangard sanatın oluşmasında etkisi oldu.

Anahtar Kelimeler: Modern Sanat, Avangard, Soyutlama, Armory Show, New York

\section{Giriş}

20. yüzyılın ilk yıllarında, Avrupa' da başlayan modern sanat hareketine Amerika henüz aşina değildi. Amerika'da peyzaj ve doğal yaşamı betimleyici gelenekçi anlayıştaki sanatçılar, 20. yüzyılın başlarında New York'ta kent yaşamı temaları ile öne çıkan bağımsız bir sanatçı grubunun (Ashcan Okulu) meydan okuması karşısında direnç gösteremedi (Zilczer, 1975: 2). Bu grubun üyeleri, endüstri devriminin getirdiği sosyal değişimler göçmen ve işçi sınıfı yaşamının sanatsal bir tema olarak değeri olduğuna inanıyor, sanatın idealize edileni yansıtmaktan ziyade gözle görülen gerçekleri tasvir etme görevi olduğunu öne sürüyorlardı. Ashcan Okulu ressamları olarak bilinen bu grup, zamanın Amerikan metropol ortamında yaşanan sosyal yoksunluk ve adaletsizlikleri konu alan resimler yapmışlardı (Velimirović, 2016).

Yirminci yüzyılın ilk başlarında Ashcan sanatçıları Robert Henri, John Sloan ve arkadaşlarının kent konulu resimleri, aynı dönemde Paris'teki Matisse, Picasso ve Braque'ın çı ğır açan resimleri ile kıyaslandığında daha az yenilikçi oldukları görünmektedir (Resim 1-2). Fakat yine de Ashcan Okulu ressamları, Avrupalı çağdaşlarından çok daha az üslupsal yenilik göstermelerine rağmen, öncü hareketleri canlandırmaya yönelik eylem içindeydiler (Zilczer, 1975: 2-3). Başka bir deyişle Avrupalı yenilikçi sanatçıların yapıtları öncü başarılar olarak kabul edilirse, 1913’ten önceki Amerikan sanatı nispeten, devrimsel stilistik değişimlerden yoksundu. 

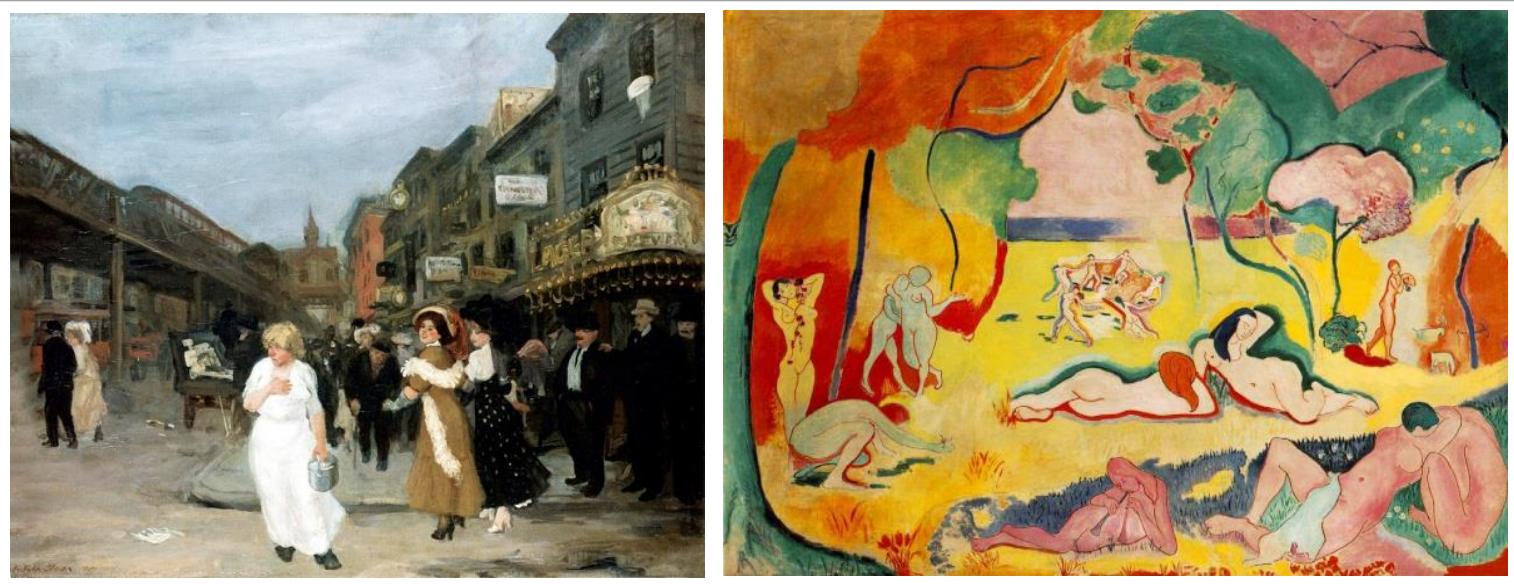

Resim 1: Joan Sloan, "Sixth Avenue and 30th Street",

Resim 2: Henri Matisse, "Le Bonheur de 1907, Tuval Üzerine Yağlıboya, 61.6 x $81.3 \mathrm{~cm}$

Vivre", 1905-1906, Tuval Üzerine

Yağlıboya, 176.5 x $240.7 \mathrm{~cm}$

Ashcan grubundan beş ressam, bağımsız üç sanatçı (Ernest Lawson, Arthur B. Davies ve Maurice Prendergast) ile birlikte "The Eight" grubunu oluşturdular. "The Eight" 1908'de akademizmin kısıtlayıcı tutumlarına karşı protesto olarak Amerikan ve modern sanatta isyanın sembolü haline gelen tarihi bir sergi düzenledi. Sergi, bir grup sanatçı tarafından jüri ve ödül olmaksızın organize edilen ilk sergi olmasından dolayı bir devrim niteliğindeydi. Bu çeşit jürisiz sergi, modern sanat tarihindeki en ünlü sergilerden biri olan Armory Show'a bir model oldu (“Artdaily", 2005).

“The Eight” grubu sanatçlarından Prendergast'ın canlı, rengârenk, mozaik benzeri resimleri grubun diğer sanatçılarının kent konulu natüralist anlayışta resimlerinden farklı olmakla kalmayıp, zamanın en modern Amerikan sanatını da temsil etmektedir (Resim 3) (Zilczer, 1975: 3).

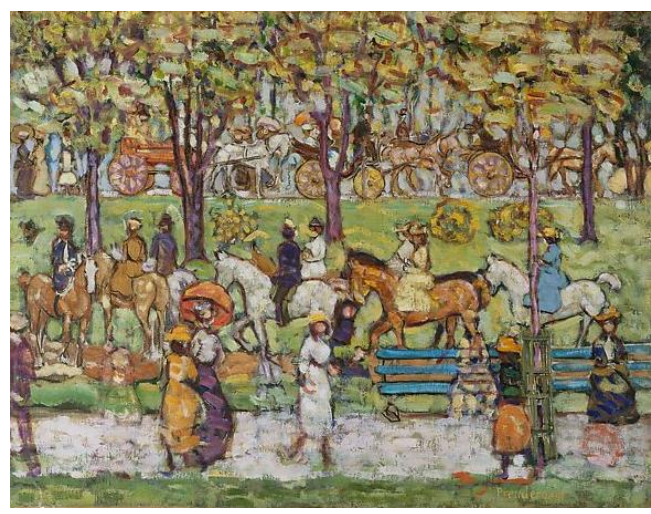

Resim 3: Maurice Prendergast, "Central Park", 1914-15, Tuval Üzerine Yağlıboya, 52.7 x $68.6 \mathrm{~cm}$

1908'in unutulmaz sergisine katılan Arthur B. Davies (Resim 4), bundan beş yıl sonra Armory Show organizasyonunda önemli bir rol oynadı. Davies'in sübjektif ifadeler yansıtan düşsel resimleri, Amerikan kentsel gerçekçi resimlerinden ziyade Fransız Sembolistlerinin anti-gerçekçi estetiğine çok daha fazla benziyordu (Zilczer, 1975: 3-4).

Ashcan Okulu ressamlarının on dokuzuncu yüzyıl geleneğine karş1 olması National Academy of Design (Ulusal Tasarım Akademisi) tarafından tecrit edilmedi. Ayrıca; fotoğrafçılığın Amerikan sanatı bünyesinde güzel sanatların bir dalı olarak modern sanatın gerçekçi olmayan 
eğilimine karşıı, tamamlayıcı bir alternatif olarak kabul edilmesi estetik tartışmayı da teşvik etti. 1903'te fotoğrafçı Alfred Stieglitz, en başından beri yeni bir sanat olarak tanıttığı fotoğraf ve sanat eleştirisi konusunda "Camera Work" da makaleler yayınlamaya başladı. 1905'te modern sanatın tartışmalı ve devrimci yönlerini sürekli olarak sunan tek galeri olan Little Galleries of the PhotoSecession (291) adını verdiği galerisinde, Avrupalı modernistlerin uzun bir silsilesini Amerika'ya tanıttı (Resim 5) (Brown, 1972: 39; Zilczer, 1975: 4; Zimlich, 2006: 1231). Stieglitz'in periyodik olarak yayınlanan "Camera Work" dergisi, Amerikalı, Avrupalı sanatçılar, eleştirmenler ve yazarlar tarafından yeni estetik teorilerin tanıtılması için bir forum haline gelirken, "Galeri 291" sanatta eleştirel, teorik ve felsefi görüş alışverişi haline geldi ("All About Photo", t.y.).

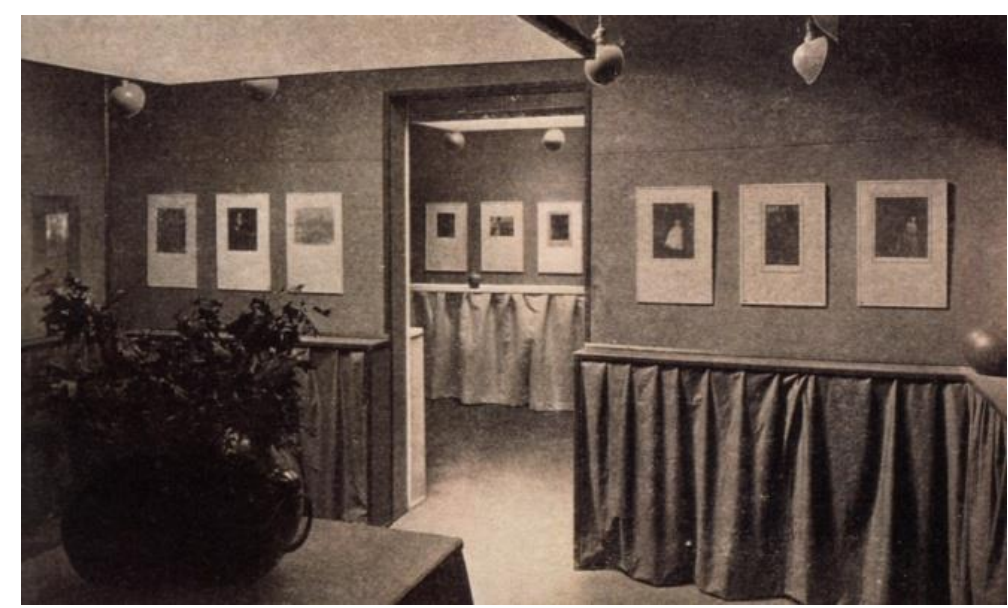

Resim 5: Alfred Stieglitz, "The Little Galleries of the Photo-Secession” sergi açıllş̧ı, 1906

1907 yılında Stieglitz kendi galerisinde fotoğrafların yanı sıra resimler de sergilemeye başladı (Resim 6). Bir yıl sonra Stieglitz, Eduard Steichen'in de büyük çabalarıyla fotoğraf ve modern sanata olan ilgilerini yansıtan bir dizi sergi gerçekleştirdi. Rodin'in çizimleri ile birlikte Matisse'in suluboya ve desenleri ilk kez Amerika'da sergilendi (Bry, 1974: 691; Zilczer, 1975: 4; Zimlich, 2006: 1231). Başta Alfred Stieglitz olmak üzere, çevresindeki sanatçılar ve eleştirmenler Amerikan modern sanatı için emsali görülmemiş bir hareketin çekirdeğini oluşturdular (Zilczer, 1975: 112).

Stieglitz, batı sanatını ve akademik geleneğini taklit etmeye karşı, mücadelesinin öneminin kat be kat farkındaydı. Böylece, Stieglitz'in Photo-Secession hareketi Armory Show'dan önceki yıllarda hızlıca avangard hareketin ikinci bir çekirdeği olarak yer aldı (Mellquist'den aktaran Zilczer, 1975: 4-5). 


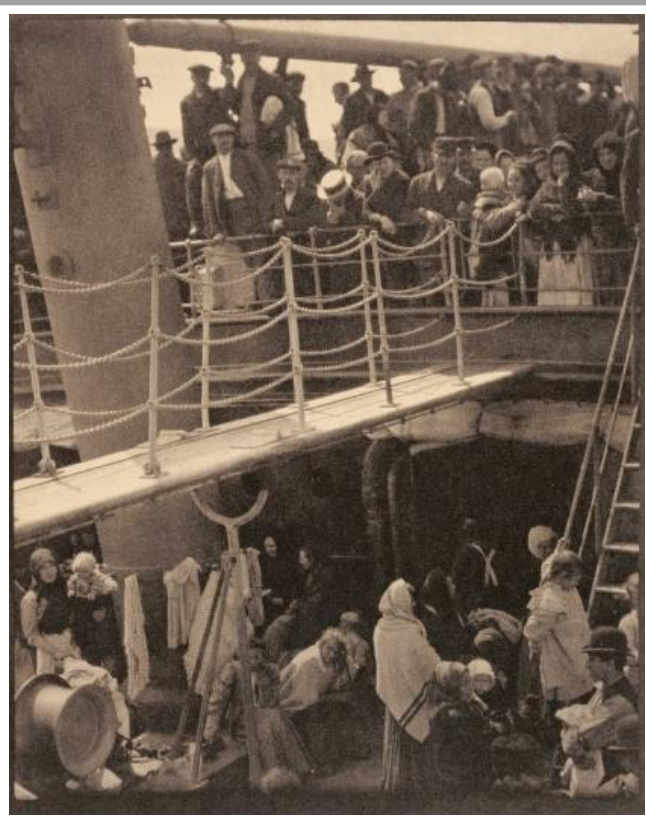

Resim 6: Alfred Stieglitz, "Güverte", 1907, Fotogravür, 35.5 x 26.4 cm

1911 başından itibaren 1912 boyunca Stieglitz, "291” de çı̆̆ır açan modern sanat sergileri düzenledi ve "Camera Work" dergisinin sayfalarında fotoğrafla birlikte yeni sanatı tanıttı. 1912 yazına gelindiğinde, fotoğrafik olmayan sanatla o kadar büyülenmiști ki, sadece "Camera Work" dergisinin bir sayısı (A ğustos 1912) Matisse ve Picasso'ya ayrılmıștı (Stieglitz, 2008: 7, 16-18, 3132). 1912'nin sonlarında ressam Walter Pach, Walt Kuhn, Arthur B. Davies modern sanat sergisi düzenledi ve Stieglitz "Galeri 291"den az sayıda modern sanat eserini sergilenmek üzere ödünç verdi. Stieglitz ayrica Claude Monet, Mabel Dodge, Isabella Stewart Gardner, Odilon Redon ile birlikte Onursal Eş Başkan olarak listelenmeyi kabul etti. Şubat 1913'te New York'ta Armory Show'un açılması modern sanat adına bir dönüm noktası oldu ve çok geçmeden kent genelinde önemli bir tartışma konusu haline geldi. Stieglitz, 291'de modern eserlerin sergilenmesine sponsor olması son beş yılda serginin popülaritesinin bir kanıtı olduğunu gördü (Eversole, 2005: 13; "Wikipedia", t.y.). Armory Show'un kazanmış olduğu popülarite gibi Stieglitz'in 291'de kendi fotoğraflarından oluşan serginin başarısı da şahlandı. Daha sonra ki yazılarında, insanların hem fotoğrafları hem de modern tabloları aynı anda görmeleri için bir firsat sunduğunu, aynı zamanda bu iki medyanın amacını halka ve öğrencilere modern sanatı açıklanması adına en iyi fırsat olduğunu belirtti ("Wikipedia", t.y.).

\section{Armory Show Öncesi}

Gelenekçi birkaç sanat derneğinden ibaret Amerikan sanat arenasının yetersizliğinden rahatsızlık duyan genç sanatçılar, sıklıkla bir araya gelerek çözüm odaklı düşünmeye koyuldular. $\mathrm{Bu}$ sanatçılar Amerika'daki tek sanat kuruluşu olarak National Academy of Design (Ulusal Tasarım Akademisi)'nin stabil ve tutucu yapısını eleştiriyor, durağanlıktan rahatsızlık duyuyorlardı (Baraz, 1998: 2; Erden, 2016: 290). Haklı olarak, himaye ve sergileme konusunda Amerika'da sanatın ölümün eşiğine geldiğine inanıyorlardı. Eski sanatçıların yanı sıra sanat piyasasına yabancı şahsiyetlerin hakim olmasından dolayı genç sanatçılar satışlardan muzdariplerdi. Ayrıca; mütevazı bir tavırla, kendi eserlerini halkın dikkatini çekecek şekilde sunulması gerektiğini hissederek, biraz da milliyetçi gururla, Amerikan sanatının ses getirmesinin gerekliliği konusunda 1srar ettiler (Brown, 1972: 47).

1911 yılında dört genç Amerikan sanatçısı (Henry Fitch Taylor, Jerome Myers, Walt Kuhn ve Elmer MacRae) tarafından başlatılan sergi projesi şaşırtıcı bir biçimde olağanüstü bir etki yarattı 
(Baraz, 1998: 2; Scott ve Rutkoff, 1999: 58). Projeyi başlatan genç nesil sanatçılar arasında Amerikan sanatındaki yeni gelişmeleri popülerleştirmek istenciyle Amerika'nın çağdaş sanat başarısının kapsamına dair halkta bir farkındalık oluşturulması gerektiği hissi uyandı. Bu üç sanatçının galeri müdürüyle yaptığı konuşmalardan Henry Fitch Taylor, büyük bir Amerikan sanatı sergisi fikrini ortaya att1 (Brown, 1972: 47; Erden, 2016: 290).

\section{Armory Show}

Amerikan Ressamlar ve Heykeltraşlar Derneği (AAPS) tarafından 17 Şubat - 15 Mart 1913 tarihleri arasında New York'ta 69. Regiment Silahhanesi'nde açılan Armory Show (Uluslararas1 Modern Sanat Sergisi), Amerikan sanatı üzerinde güçlü bir şok etkisi yarattı. Hiç şüphesiz bu, o ana kadar Amerika'da gerçekleştirilmiş olan en önemli sergi oldu (Resim 7-8).

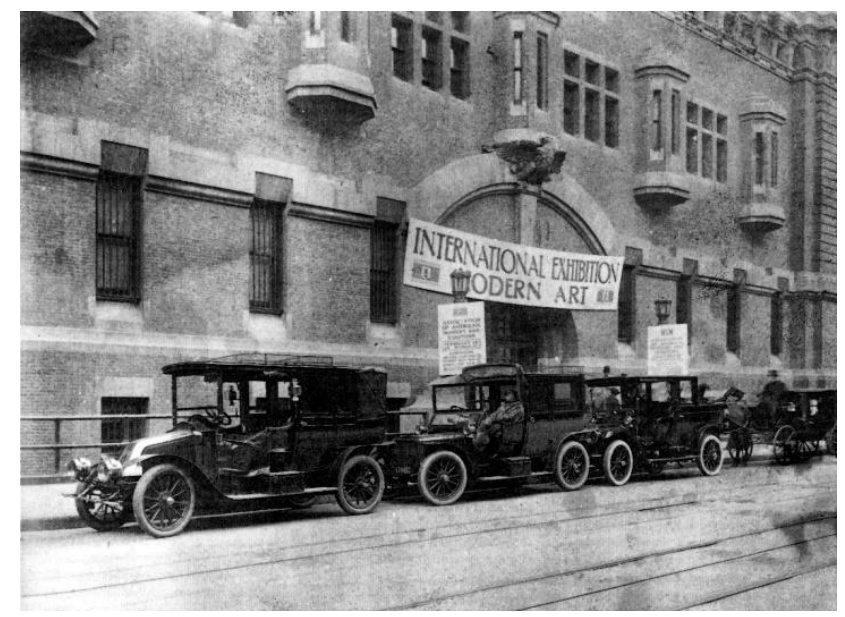

Resim 7: Armory Show, "69th Regiment Armory”, New York, 1913

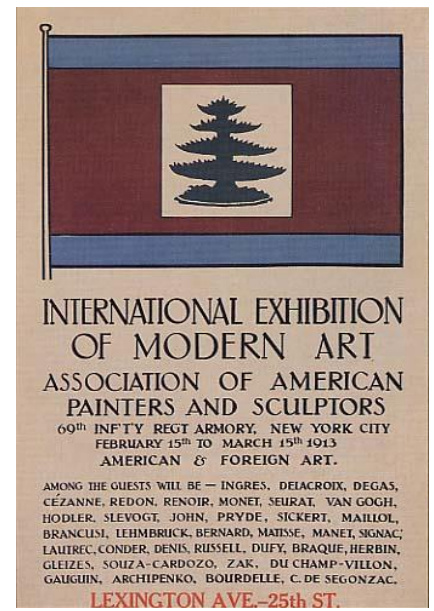

Resim 8: Armory Show sergi afişi

AAPS'nin başkanlığına seçilen Arthur B. Davis 19. yüzyılda Fransız resim geleneğinin kurucuları olarak temsil edilen Ingres ve Delacroix'dan modernizme kadar olan sanat yapitlarından oluşan bir sergi tasarladı. Bu sergiyi tasarlamaktaki amacını anlatırken; sergilenen eserlerde betimlenen kavramları ve semantik yapıları irdelenmek üzere gözler önüne sermek olduğunu dile getiriyordu. Davies düzenlediği bir çizelgede, sanatçıları Klasikçiler, Realistler ve Romantikler olarak üç ana kategoriye ayırarak kronolojik bir sınıflandırma yaptı (Baraz, 1998: 5; Brown, 1972: 49, 52; Zilczer, 1975: 22).

$\mathrm{Bu}$ siniflandırmaya göre:

Klasikçiler; Ingres, Corot, Puvis de Chavannes, Degas ve Seurat,

Realistler; Courbet, Manet, Monet, Sisley, Pissarro, Signac, Cassatt, Toulouse-Lautrec ve Morisot,

Romantikler ise; Delacroix, Daumier, Redon ve Renoir olarak sıralandırıldı (Resim 9) (Brown, 1972: 49).

Sergide yer alan ancak çizelgede listelenmeyen diğer on dokuzuncu yüzyıl usta ressamları Goya, Whistler, Rodin ve Monticelli'nin yanı sıra İsviçreli Hodler idi. Sergide Post-Empresyonist sanatçılardan Cézanne, Van Gogh ve Gauguin'e oldukça fazla yer verildi (Brown, 1972: 49). 


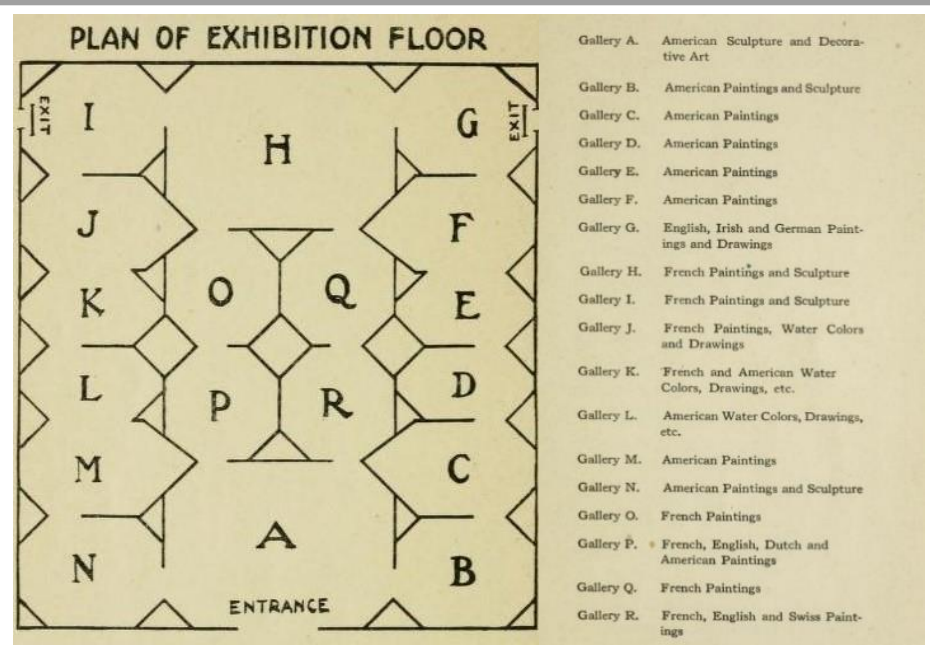

Resim 9: Armory Show sergisinin kat planı

Çağdaş sanatçılara ayrılan bölümde:

Geç İzlenimcilerden; Vuillard, Bonnard ve Denis,

Fovistlerden; Matisse, Marquet, Derain, Vlaminck, Rouault, Dufy ve Friesz,

Kübist ressamlardan; Picasso, Braque, Duchamp, Gleizes, Léger, Picabia ve Villon,

Heykeltıraşlardan; Archipenko, Duchamp-Villon ve Manolo,

Orfist sanatçılardan; Delaunay,

Amerikan Senkromist sanat hareketini de göçmen Morgan Russell temsil etmekteydi.

$\mathrm{Bu}$ kategorilere kolayca girmeyenler arasinda:

Ekspresyonist'lerden; Munch, Kandinsky ve Kirchner,

Heykeltraşlardan; Lehmbruck, Maillol, Brancusi,

Primitif sanatç1lardan; Rousseau,

Laurencin, Dufrenoy, Valloton, Segonzac ve Fresnaye.

Die Brücke, Der Blaue Reiter grupları ve Fütüristlerin hariç tutulması dışında, çağdaş Avrupa sanatının bu seçkisi günümüz modernizm tanımımızın temelini oluşturmaktadır. Kabul etmeliyiz ki, Armory Show yarattığı duyumun yanı sıra, sergileme işini mükemmel bir şekilde başard1 (Brown, 1972: 49).

Dört hafta süren bu şaşaalı sergide, 25 ülkeden tanınmış 308 sanatçının 1300' den fazla eseri sunuldu. Sergiye katılan sanatçıların yarısından fazlasını ABD'li sanatçılar oluştururken, Avrupalı sanatçılar ise 1/3'ünü oluşturuyordu. Sergi dört haftalık sürenin sonunda yaklaşık olarak 90.000 kişilik izleyici sayısına ulaşıyordu (Braden, 2009: 442; Brown, 1988: 110; Zilczer, 2011: 133). İşin tuhafi ise, sergiye olan ilgi ilk iki hafta boyunca oldukça hayal kırıklığı yarattı. Ancak; basın ve halka ulaşılmasıyla üçüncü haftadan sonra yoğun izleyici kitlesinin sergiye olan ilgisi arttı ve şaşırtıcı bir başarı sağlandı (Brown, 1972: 49). Paul Cézanne, Vincent van Gogh, Marcel Duchamp, Henri Matisse, Mary Cassatt, James Whistler ve Pablo Picasso gibi sanat tarihinde yer alan en ünlü sanatçıların eserleri de sergide yer almaktaydı. 


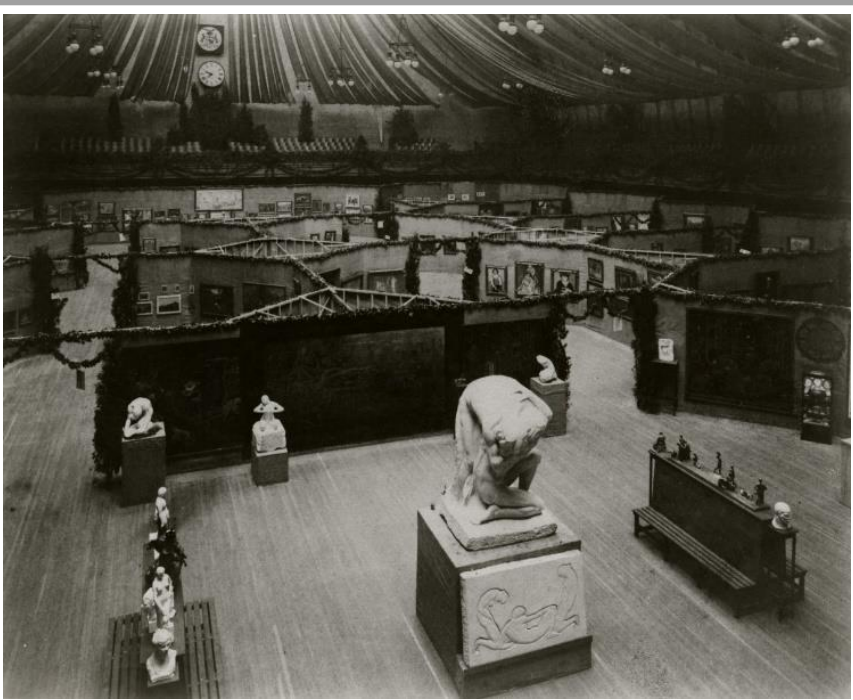

Resim 10: 1913 Armory Show sergisinin iç görünümü, New York

Armory Show'da sergilenmiş olan eserler, ABD'de temsil edilen önceden hayal edilmemiş modernizmin avangard sanatçı eserlerinin ilk dalgasını oluşturuyordu. Sergide yer alan modern yapitlar (Empresyonizm, Ekspresyonizm, Fovizm, Kübizm ve Fütürizm) geleneksel sanatın gerçekçi, temsili betimlemelerinin tam aksine konu, renk ve materyal kullanımı ile soyutlamaya doğru bireysel yorumlamaların göstergesiydi (Resim 10).

Armory Show'un başlangıç tarihi ihtilaf ve hizipçilikle doludur. "Armory Show'la ilgili olarak Amerikan halkı, basın ve entelektüeller çok karşı1t tepkilerde bulunmuşlar ve Amerikan basınında sergi ile ilgili olarak aşırı eleştiriler yer almıştı" (Baraz, 1988: 5). İnsanların galerileri doldurması karşısında akademik gelenekçiler kaba, agresif bir tutum sergilediler (Brown, 1972: 49).

Gelenekçi anlayışa karşı modern sanat tartışmanın odak noktasıydı. İlginçtir ki, farklı zamanlarda zıt görüşlere sahip iki taraf da çelişkili sonuçlara vardı. Örneğin, gelenek meselesinde modernistler, yeni sanatın geçmişin saygın geleneklerine dayandığını iddia ettiler. Ve devamla, Akademisyenler tarafından önemsenmeyen ya da yok olmaya yüz tutmuş bütün sanatların köklerinin estetik yasalardan kaynaklandığını ileri sürdüler. Akademik kurallara bağlı gelenekten olanlar bunu görmezden gelip nahoş bir şeymiş gibi davranabilirlerdi, ama açıkçası bu dünyada önü alınamayacak bir şeydi (Brown, 1972: 47, 49, 52).

Çatışmanın alanını genişletme konusunda mantıksal veya bilgisel bir düzlemde yürütülmediği için Armory Show'dan çıkan eleştirel tartışma, estetik düşünceyi açıklı̆̆a kavuşturmada yeterince başarılı olamadı. Modern sanat konusundaki tartışmalar herkes tarafindan yapılabilir hale geldi ve her ilave teori konusu sadece modern sanatın değil aynı zamanda sanatın da çeşitlenmesine yardımcı oldu. Hatta en ateşli karşıtlar bile Armory Show'un sanatı topluma yayma konusunda sınırsız/ölçüsüz bir hizmet gerçekleştirdiğini fark ettiler (Brown, 1972: 49, 52).

\section{Sonuc}

19.yy sonlarından 20.yy başına kadar ABD ekonomik, sosyal, kültürel ve endüstriyel anlamda birçok değişim geçirdi. Avrupa'da yaşanan siyasi güvensizliğin yarattığı tedirginliğe karşın Amerika'da parlayan ekonomik refah ülkeye büyük göç dalgaları yarattı. Avrupalı sanatçıların da New York'a gelip faaliyetlerini sürdürmesiyle Amerikan gelenek ve kültürünün kalıcı etkisi zayıflamaya başladı. Sanatçılar zaman zaman belirli mekânlarda bir araya gelerek sanatsal paylaşımlarda bulunuyor ve oluşturdukları potansiyelle Amerikan gelenekçi sanatı karşısında yeni anlayışlarla ortaya çıkmaya çalışıyorlardı. Üretilen eserler, açılan galeriler ve sergiler sanat piyasası 
oluşturuyor, New York'un sanatın merkezi olma yolunda Amerika giderek küreselleşen uluslararası sanat sahnesine dönüşmeye başladı.

20. yy başında Ashcan Okulu ve The Eight olarak adlandırılan bir grup sanatçı, Amerikan modernizmin çekirdeğini oluşturdu. Bir taraftan sanatçı Robert Henri, "Ashcan School", "The Eight" çevresinde toplanan grup Akademi ile olan bağlarını koparırken, diğer taraftan Fotoğrafçı Alfred Stieglitz'in "Photo-Secession" hareketi (fotoğrafi sanatın bir dalı olarak sergilerinde yer vermesi) ve "Camera Work" dergisi modern Amerikan sanatını oluşturma yolundaki çabaları sonuç verdi. Stieglitz'in New York'ta "Galeri 291"de Avrupa'nın ünlü sanatçılarından Paul Cézanne, Henri Matisse, Pablo Picasso'nun eserlerini yepyeni bir kitleye tanıtmas1, ABD'de modernizmin yükselişinde oynadığı öncü rol göz önüne alındığında Armory Show sergisi, hem geçmişle hem de bugün ile doğrudan ve yapılandırılmış bir ilişki içinde olduğu görülür.

Avrupa'dan getirilen resimlerin sergilenmesi Amerikalı sanatçılar arasında yıllar süren deney, deneyim sonucu olarak modern sanatı hazırlayan birçok önemli gelişme ve değişime konu olan bir süreci başlattığına tanık olmaktayız. Bunlara ek olarak Amerikan Ressamlar ve Heykeltraşlar Derneği tarafından başlatılan sergi projesinin Amerika'da yeni sanatı teşvik etme hedefini destekleyerek Avrupa modern sanat yapıtlarının Amerikalı sanatçıların görsel deneyim ve farkındalık oluşturması yönündeki çabaları Amerikan sanatçıları adına cesaretlendirici adımlardı. Bu adımların en gözdelerinden biri de Armory Show sergisinin Amerikan sanatı ve sanatçısı üzerindeki etkileridir.

Armory Show'un modern Amerikan sanatını oluşturmadaki en önemli başarısı farklı bir kıtadan ithal edilmiş olan eserlerin yarattı̆ğ dönüşümün tarihsel önemi ile ölçülür. Avrupa'dan gelen seçkin modern görsel sanat yapıtları Amerikan sanatçıları üzerinde yepyeni form estetiği algısına yol açtı. Kavram ve felsefeye dayalı yeni estetik biçimlerin tanıtılması söz konusu oldu. Sanatta yepyeni estetik varlık bilincinin algıda yarattığı farkındalık duygusu Amerikan sanatçıları, entellektüelleri ve izleyiciler açısından değişimin başlangıcını oluşturuyordu.

Avrupa modern resmi Amerika'da ünlü sanat müzelerinde izleyiciye duygusal ve psişik durumlarına ışık tutarak, yeni pencerelerden bakış açıları kazandırdı. Armory Show ve sonrasında ortaya çıkan sergiler, Amerikalı sanat küratörlerinin estetik bilinçlerini değiştirmesine vesile oldu. Ayrıca Armory Show Amerika'da görsel sanat piyasası oluşturarak tecimsel etki de yarattı. Armory Show'un başarısından sonra, yeni sanat galerileri, yayınlar, dernekler ve modern sanat sergileri hızla çoğaldi.

Amerikan genç kuşak sanatçıları Armory Show sergisinden aldıkları ilhamla Avrupa'ya giderek sanata olan bakış açılarının yönü değişti. Armory Show sergisi ile ABD sanatının gelenekçi anlayışa olan eğilimi zayıflarken, modern sanata olan eğilimlerde belirgin bir yükseliş görüldü.

Armory Show'un tarihsel önemi ABD sanat tarihinde eşsizdir. Kısaca, ABD tarihinin en önemli sanat sergisi olarak kabul edilen Armory Show, avangard sanat dünyasında dönüm noktası oldu. Amerika'da Modern sanat hayatın içinden ve her safhasından yaşamı sanat ile bağdaştırmayı başardı.

\section{Kaynakça}

All About Photo. (t.y.). Alfred Stieglitz. https://www.all-aboutphoto.com/photographers/photographer/22/alfred-stieglitz Erişim Tarihi: 26.12.2019

Artdaily. (2005, 27 Eylül). Robert Henri and his circle at Chazen Museum. https://artdaily.cc/news/15039/Robert-Henri-and-His-Circle-at-Chazen-Museum Erişim Tarihi: 01.11.2019 
Baraz, Y. (1998). Armory Show. Genç Sanat Güzel Sanatlar Dergisi, 51, 1-7.

Braden, L. E. A. (2009). From the Armory to academia: Careers and reputations of early modern artists in the United States. Poetics: Journal of Empirical Research on Culture, the Media and the Arts, 37(5), 439-455.

Brown, M. W. (1972). American painting: From the Armory Show to the depression. Princeton University Press.

Brown, M. W. (1988). The story of the Armory Show. New York: Abbeville Press.

Bry, D. (1974). Alfred Stieglitz. The New Encyclopaedia Britannica içinde (Vol. 17, s. 690-691). Encyclopaedia Britannica.

Erden, E. O. (2016). Modern sanatın kısa tarihi. İstanbul: Hayalperest Yayınevi.

Eversole, T. (2005). Alfred Stieglitz's camera work, and the early cultivation of American modernism. Journal of American Studies of Turkey, 22, 5-18. https://dergipark.org.tr/en/download/article-file/996478

Scott, W. B., Rutkoff, P. M. (1999). New York modern: The arts and the city. Baltimore and London: The Johns Hopkins University Press.

Stieglitz, A. (2008). Camera work: The complete photographs 1903-1917. Taschen.

Velimirović, A. (2016, 28 Kasim). Ashcan school of art and the pictures of modern New York. https://www.widewalls.ch/ashcan-school/ Erişim Tarihi: 01.11.2019

Wikipedia. (t.y.). Alfred Stieglitz. https://en.wikipedia.org/wiki/Alfred_Stieglitz Erişim Tarihi: 06.01.2020

Zilczer, J. K. (1975). The aesthetic struggle in America, 1913-1918: Abstract art and theory in the Stieglitz circle (Doctoral dissertation). University of Delaware.

Zilczer, J. (2011). Armory Show. Joan Marter (Ed.), The grove encyclopedia of American art (Vol. 1, s. 132-134) içinde. Oxford: Oxford University Press. https://books.google.com.tr/books?id=sPGdBxzaWj0C\&pg=PA134\&lpg=PA134\&dq=Zilc zer,+Judith.+Armory+Show\&source=bl\&ots=qcjjGGwMyi\&sig=ACfU3U3prm6tWD82js 34WAGNCOIk-

5y02w\&hl=tr\&sa=X\&ved=2ahUKEwis54bcgdPmAhXKKFAKHaBUC98Q6AEwA3oEC AgQAQ\#v=onepage\&q=Zilczer\%2C\%20Judith.\%20Armory\%20Show\&f=false

Zimlich, L. E. (2006). Photo-secession. Lynne Warren (Ed.), Encyclopedia of twentieth-century photography (s. 1229-1232) içinde. New York: Routledge. https://books.google.com.tr/books?id=31VsBgAAQBAJ\&pg=PA1238\&lpg=PA1238\&dq= Marianne+F.+Margolis, + ed., + Camera + Work: $+\mathrm{A}+$ Pictorial+Guide\&source $=\mathrm{bl} \&$ ots $=\mathrm{j}$ Vxb5 u6A8E\&sig=ACfU3U07ToEV2aeN_ttyfB1eNcipc24I3w\&hl=tr\&sa=X\&ved=2ahUKEwjD nLf4seHoAhUIyYUKHU6rDxUQ6AEwC3oECAoQKw\#v=onepage\&q=Marianne\%20F. $\% 20$ Margolis\%2C\%20ed.\%2C\%20Camera\%20Work\%3A\%20A\%20Pictorial\%20Guide\& $\mathrm{f}=$ false

\section{Görsel Kaynakçası}

Resim 1: Joan Sloan, "Sixth Avenue and 30th Street", 1907, Tuval Üzerine Yağlıboya, 61.6 x 81.3 $\mathrm{cm}$ Collection of Mr. and Meyer P. Potamkin https://fineartamerica.com/featured/sixthavenue-and-thirtieth-street-john-sloan.html Erişim Tarihi: 01.11.2019 
Resim 2: Henri Matisse, "Le Bonheur de Vivre", 1905-1906, Tuval Üzerine Yağlıboya, 176.5 x $240.7 \mathrm{~cm}$ https://www.henrimatisse.org/images/gallery/joy-of-life.jpg Erişim Tarihi: 01.11 .2019

Resim 3: Maurice Prendergast, "Central Park”, 1914-15, Tuval Üzerine Yağlıboya, 52.7 x 68.6 cm https://www.metmuseum.org/art/collection/search/11804 Erișim Tarihi: 01.11.2019

Resim 4: Arthur B. Davies, "A Measure of Dreams”, 1908, Tuval Üzerine Yağliboya, 45.7 x 76.2 cm https://www.metmuseum.org/art/collection/search/10674 Erişim Tarihi: 01.11.2019

Resim 5: Alfred Stieglitz, "The Little Galleries of the Photo-Secession" sergi açılış1, 1906 https://www.wikiwand.com/en/291_(art_gallery) Erişim Tarihi: 26.12.2019

Resim 6: Alfred Stieglitz, "Güverte", 1907, Fotogravür, 35.5 x 26.4 cm https://upload.wikimedia.org/wikipedia/commons/6/6b/Alfred_Stieglitz_-_The_Steerage__Google_Art_Project\%2C_from_Getty.jpg Erişim Tarihi: 26.12.2019

Resim 7: Armory Show, "69th Regiment Armory", New York, 1913 https://www.swanngalleries.com/news/19th-20th-century-prints-drawings/2013/10/armoryshow-100-introduction/ Erişim Tarihi: 06.01.2020

Resim 8: Armory Show sergi afişi https://tr.wikipedia.org/wiki/Armory_Show Erişim Tarihi: 06.01 .2020

Resim 9: Armory Show sergisinin kan https://archive.org/details/catalogueofinter00asso/page/70/mode/2up Erişim Tarihi: 06.01 .2020

Resim 10: 1913 Armory Show sergisinin iç görünümü, New York https://www.6sqft.com/modernwomen-meet-the-females-who-founded-nycs-modern-and-contemporary-art-museums/ Erişim Tarihi: 14.01 .2020 